\title{
Protective Effect of Ocimum sanctum in Broilers Treated with High Doses of Gentamicin
}

\author{
Arivuchelvan $^{1 *}$ and S. Murugesan ${ }^{2}$ \\ ${ }^{1}$ Department of Veterinary Pharmacology and Toxicology, Veterinary College and \\ Research Institute, Namakkal -637 002, Tamil Nadu, India \\ ${ }^{2}$ Veterinary College and Research Institute, Theni, Tamil Nadu, India \\ *Corresponding author
}

\section{A B S T R A C T}

\begin{tabular}{|l|}
\hline Ke y w o r d s \\
$\begin{array}{l}\text { Nephroprotective } \\
\text { effect, Broiler } \\
\text { chicks, Ocimum } \\
\text { sanctum, } \\
\text { Gentamicin }\end{array}$ \\
\hline Article Info \\
$\begin{array}{l}\text { Accepted: } \\
\text { 15 October } 2020 \\
\text { Available Online: } \\
10 \text { November } 2020\end{array}$ \\
\hline
\end{tabular}

\section{Introduction}

Intensive poultry production with fast growing strains and high stocking densities are usually susceptible to infectious agents due to varied reasons. Antibiotics especially gentamicin is used frequently by poultry farmers at very high doses from the day of hatching to culling/marketing. The impact analysis of this practice reveals many negative effects namely failure of treatment, escalation of treatment cost, adverse effect of chemotherapeutic agents esp. organ toxicity
The present research work was carried out to study the nephro and hepatoprotective effect of Ocimum sanctum in broilers exposed to high doses of gentamicin, which is common in poultry practice of Tamilnadu. Two hundred and seventy day old broiler chicks of either sex were randomly divided into nine treatment groups of 10 each with three replicates. Different doses of gentamicin $(30 \mathrm{mg} / \mathrm{kg} \& 50 \mathrm{mg} / \mathrm{kg})$ given with single intramuscular injection, different inclusion level of Ocimum sanctum crude extract $(1 \% \& 2 \%)$ in feed were tested. The results of the study revealed that Ocimum sanctum showed dose dependant protective effect against Gentamicin induced nephrotoxicity and hepatotoxicity, which is evidenced by histopathological and gross examination. and mortality in flocks some times. Many medicinal plants showing hepatoprotective and nephroprotective activity has been used instead of drugs because of their low toxicity for the host system, adequate absorption and capability to reach the target organ without much degradation by host enzymes. Ocimum sanctum Linn. (Lamiacea) commonly known as holy basil in English, Tulsi in Hindi and Tamil is an Indian medicinal plant which is known to have ethno-medical uses such as hepatoprotective, antihyperlipidaemic, myocardial salvaging and immunostimulant 
effect in man and animals. Hence, the present was carried out to explore the possible hepatoprotective and nephroprotective effect of Ocimum sanctum in broilers treated with high doses of gentamicin.

\section{Materials and Methods}

Two seventy commercial day old, unsexed broiler straight run chicks (Vencob strain) belonging to a single hatch, obtained from a commercial hatchery at Namakkal was used for the experimental study. All the chicks were reared under standard and uniform managemental conditions throughout the experimental period of six weeks. The chicks were weighed, wing banded and reared in battery brooders.

On eighth day, the chicks were randomly divided into nine treatment groups of ten each with three replicates. Broiler starter and finisher mash, free of toxins and pesticide residues purchased from a commercial feed manufacturing unit at Namakkal was used as a basal diet for formulating the experimental diet. The broiler starter and finisher mashes were fed ad libitum to the birds from 1 - 28 and 29 - 42 days of age respectively. The birds were subjected to respective treatments from eighth day to 42nd day as per table shown below.

The crude extracts of the herbal plant Ocimum sanctum received as gratis from $\mathrm{M} / \mathrm{s}$. Himalayas, Bengaluru, and the commercially available gentamicin was used for the experimental study. A survey was conducted to fix the dose of gentamicin and was injected on 15 th day at the rate of 30 and $50 \mathrm{mg} / \mathrm{kg}$ body weight as single intramuscular injection. Other control birds received equal quantity of normal saline. Inclusion levels of plant extract were fixed as per the literature. Experimental diets containing Ocimum sanctum (crude extract) at 1 and 2 per cent levels were prepared and fed to the respective treatment groups. At the end of forth and sixth week six birds from each treatment group were sacrificed (two from each replicate).

\begin{tabular}{|c|c|c|}
\hline S. No & Treatment & Experimental group \\
\hline $\mathbf{1}$ & T1 & Normal control \\
\hline $\mathbf{2}$ & T2 & Gentamicin- 30mg/kg \\
\hline $\mathbf{3}$ & T3 & Gentamicin $-50 \mathrm{mg} / \mathrm{kg}$ \\
\hline $\mathbf{4}$ & $\mathrm{T} 4$ & Ocimum sanctum $-1 \%$ level \\
\hline $\mathbf{5}$ & $\mathrm{T} 5$ & Ocimum sanctum $-2 \%$ level \\
\hline $\mathbf{6}$ & $\mathrm{T} 6$ & Gentamicin $-30 \mathrm{mg} / \mathrm{kg}+$ Ocimum sanctum $-1 \%$ level \\
\hline $\mathbf{7}$ & $\mathrm{T} 7$ & Gentamicin $-50 \mathrm{mg} / \mathrm{kg}+$ Ocimum sanctum $-1 \%$ level \\
\hline $\mathbf{8}$ & $\mathrm{T} 8$ & Gentamicin $-30 \mathrm{mg} / \mathrm{kg}+$ Ocimum sanctum $-2 \%$ level \\
\hline $\mathbf{9}$ & $\mathrm{T} 9$ & Gentamicin $-50 \mathrm{mg} / \mathrm{kg}+$ Ocimum sanctum $-2 \%$ level \\
\hline
\end{tabular}

Gross pathological changes of liver and kidney were studied after sacrificing the birds at the end of fourth and sixth week. The representative pieces of liver and kidney from the above trail were collected in $10 \%$ buffered neutral formalin for histopathology and sections were prepared and stained by haematoxylin and eosin.

\section{Results and Discussion}

\section{Gross pathology (kidney and liver)}

Kidney of gentamicin control showed dose dependent changes grossly. At the end of fourth week, the lower dose of gentamicin (T2) showed oedema and mild congestion (Plate 1a) whereas the higher dose (T3) 
exhibited oedema and severe congestion (Plate 1b). Ocimum sanctum control groups and the other treatment groups showed no gross pathological changes at the end of fourth as well as sixth week. There were no gross pathological changes in the liver of all the groups at the end fourth and sixth week.

\section{Histopathology (kidney and liver)}

\section{Kidney}

The kidney of normal control group revealed normal architecture of tubules and intact epithelium (Plate 2). The gentamicin control group (T2) showed detachment of epithelium from basement membrane and pyknotic nuclei and mild changes of tubular epithelial cells (Plate 3). The group T3 treated with higher dose of gentamicin depicted severe necrotic changes of lining epithelium of tubules, inter tubular hemorrhages and moderate degree of vacuolar degeneration (Plate4). Ocimum sanctum control groups T4 and T5 revealed normal architecture of tubules without any changes (Plate 5 and 6)The treatment group T6 showed mild necrotic changes in tubular epithelium with hydropic degeneration (Plate 7) while the group $\mathrm{T} 7$ showed moderate necrotic changes and disruption of tubular architecture (Plate8). Kidney of the treatment group T8 revealed normal architecture of kidney tubules with intact epithelium (Plate 9). The group T9 also revealed normal architecture of tubules but slight intertubular cellular infiltration was noticed (Plate 10).

\section{Liver}

The histopathology of liver of normal control group $\mathrm{T} 1$ showed normal hepatic plates and central vein (Plate11). Though there was no any gross change in gentamicin control group, histologically moderate alterations were observed. The liver of gentamicin control group (T2) revealed mild disruption of hepatic plates and sinusoidal congestion (Plate 12) whereas the higher dose of gentamicin (T3) produced moderate disruption of plates and macrovacuolar changes of hepatocytes (Plate13). Ocimum sanctum control groups T4 and T5 revealed normal hepatic plates and central vein (Plate 14 and 15). The treatment group T6 showed mild disruption of hepatic plates and degeneration of hepatocytes (Plate 16) while the group T7 revealed moderate disruption of hepatic cords and sinusoidal oedema (Plate 17). The group $\mathrm{T} 8$ revealed normal histological features of hepatic parenchyma (Plate 18). Slightly disrupted hepatic plates and normal hepatocytes were noticed in treatment group T9 (Plate 19).

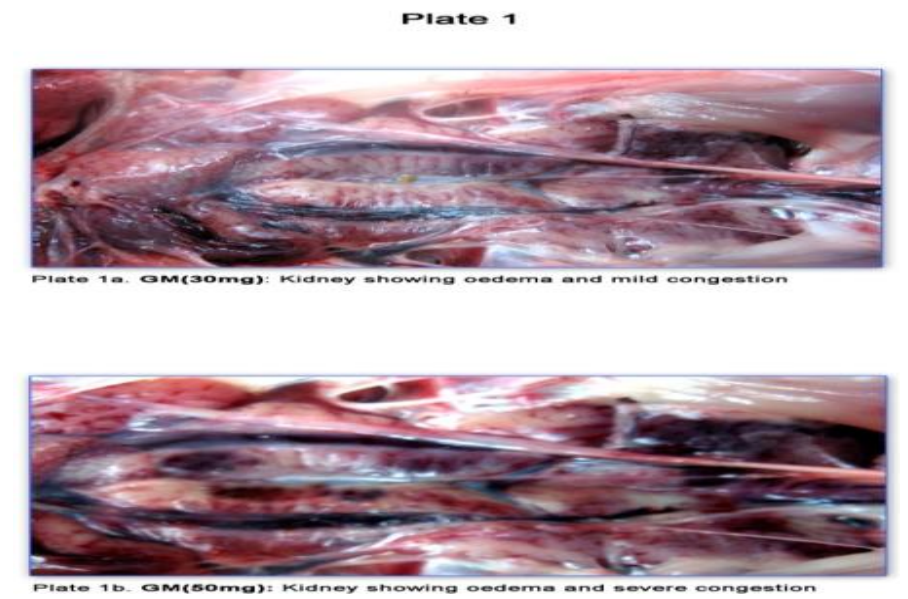



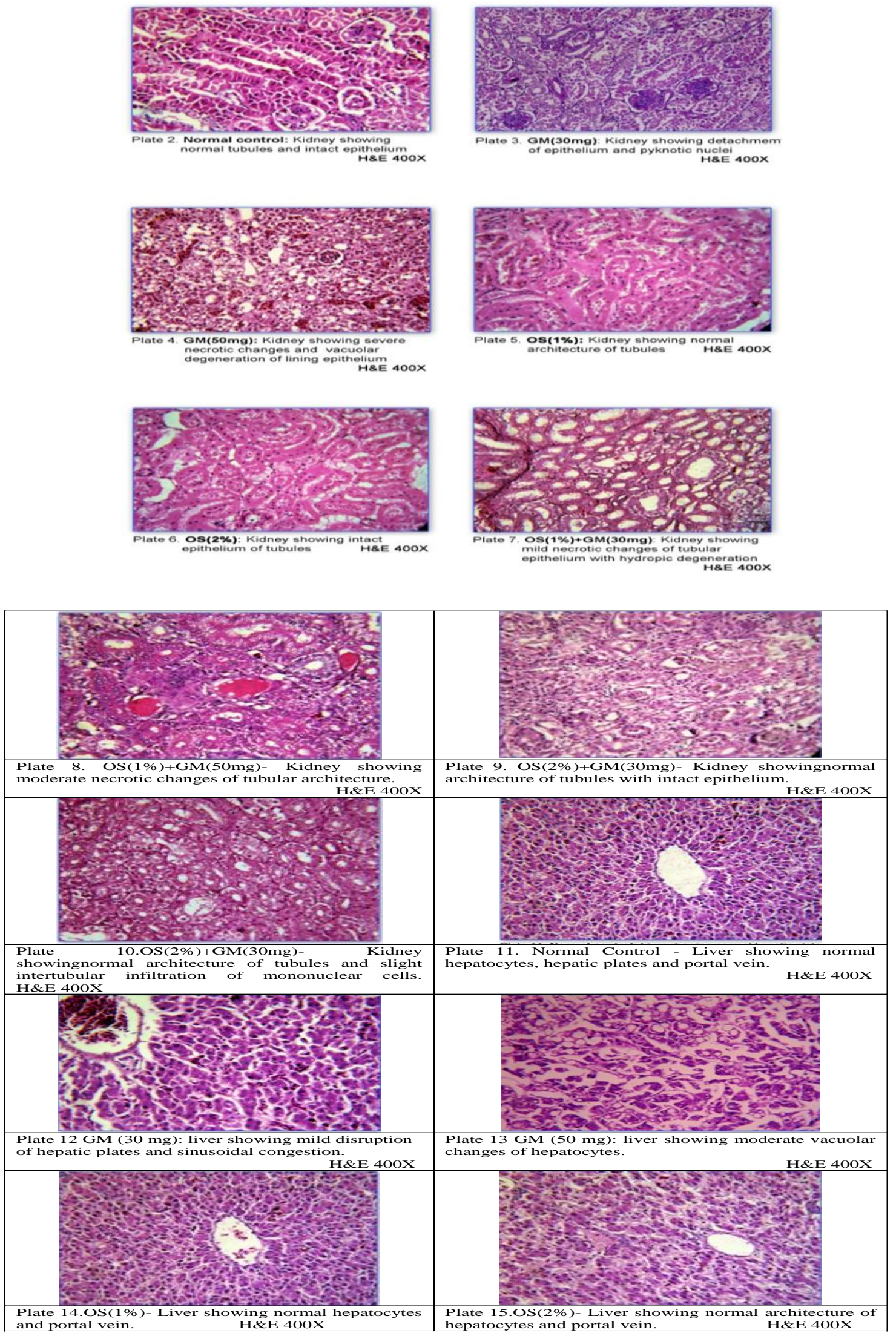


\section{Gross changes (kidney and liver)}

Gentamicin treated kidney showed mild to moderate congestion and multifocal haemorrhage and mottling at the end of fourth week. Similar findings were reported by Javed et al., (2008) in chicks given $50 \mathrm{mg} / \mathrm{kg}$ and higher dose of gentamicin wherein the kidney was enlarged, congested and had focal haemorrhages on the surface. Ocimum sanctum control and other treatment groups showed no gross pathological changes at the end of fourth week. Normal appearance of kidney in treatment groups indicates the protective effect of Ocimum sanctum. At the end of the trial no gross lesions were detected in the kidney of all the treated groups. The liver of all the treatment groups were normal and no gross changes were noticed at the end of fourth and sixth weeks.

\section{Histopathological changes (kidney and liver)}

The results of the histopathological studies of kidney from gentamicin control group revealed detachment of epithelial cells from basement membrane and mild to severe necrotic changes of tubular epithelium with varying degree of vacuolar changes. Similar observations were made by many authors with different degree of kidney damage by gentamicin (Ginpreet Kaur et al., 2009; Gupta, et al., 2007 and S. Charan, 2007). Exploring the potentials of Ocimumsanctum (Shyamatulsi) as a feed supplement for its growth promoter activity in broiler chickens.

Histopathological changes such as tubular necrosis, desquamation and degeneration of proximal tubular cells, cell infiltration in the interstitium and hyaline cast formation in lumens of tubules were noticed by Hayashi $e t$ al., (1988) in the kidney of gentamicin treated rats. He further reported that the cell lesions were found in proximal tubular cells and not in distal tubular cells. Gentamicin concentrates in the lysosomes of kidney proximal tubular cells inhibiting the activities of phospholipases $\mathrm{A}$ and $\mathrm{C}$ including $\mathrm{a}$ phospholipidosis characterized by the formation of myeloid bodies (Samadian et al., 1993; Ginpreet Kaur et al., 2009). Gentamicin administration resulted in dose dependent increase in the tubular destruction which was prevented by the Ocimum sanctum treatment. Ocimum sanctum treatment protected tubular epithelial cells from necrotic changes and intertubular cellular infiltration. It has been shown that gentamicin exert their adverse renal effects by generation of reactive oxygen species (Hadjipour et al., 2008). Ocimum sanctum by virtue of its antioxidant property might have cleared the reactive oxygen species generated by gentamicin and thus ameliorates the adverse effect of gentamicin in a dose dependent manner (Vara Prasad Reddy et al., 2009, Tabassum et al., 2009 and Gatne et al., 2010).

\section{References}

Gatne, H. 2010. Immunomodulatory effect of Stresroak in broilers. Indian J. Exp. Biol., 3(2): 110-117.

GinpreetKaur, C. Meena, A. Veeranjaneyulu and S. S. Agarwal, 2009. Evaluation of hepatoprotective activity of Ocimum sanctum in HepG2 cell line.Arch. Pharm. Sci. Res., 1(1): 125-130.

GinpreetKaur, C. Meena, A. Veeranjaneyulu and S. S. Agarwal, 2009. Evaluation of hepatoprotective activity of Ocimum sanctum in HepG2 cell line.Arch. Pharm. Sci. Res., 1(1): 125-130.

Gupta, G and S. Charan, 2007. Exploring the potentials of Ocimum sanctum (Shyamatulsi) as a feed supplement for its growth promoter activity in broiler chickens. Indian J. Poult. Sci., 42(2): 123-127.

Hadjipour, N., S. M. Naghiv and M. 
Davanian, 2008. Histopathological study of vitamins $\mathrm{A}$ and $\mathrm{C}$ effects on the reduction of gentamicin nephrotoxicity in rats. J. Anim. Vet. Adv., 7(9): 10381041.

Huy, T. B. P., A. Meulemans, M. Wassof, C. Manuel, O. Sterkers and C. Amiel, 1983. Gentamicin persistence in rat endolymph and perilymph after a two day constant infusion. Antimicrob. Agents Chemother., 27(2): 344-346.

Javed, U., M.K. Saleemi, M. Z. Khan, A. Khan and I. Javed, 2008. Pathological effects of gentamicin in growing broilers. Proceedings, The $15^{\text {th }}$ congress of FAVA. pp. o17 -o18.

Samadian, T., A. R. Dehpour, S. Amini and P.
Nouhnejad, 1993. Inhibition of gentamicin induced nephrotoxicity by Lithium in rat. Histol. Histopathol., 8(1): 139-147

Tabassum I., Z. N. Siddiqui and S.J. Rizvi, 2009. Protective effect of Ocimum sanctum on lipid peroxidation, nucleic acids and protein against restraint stress in male albino rats. Biol. Med., 1(2): 4253.

Vijayakumar, K., M. U. R. Naidu, Anwar A Shifow and K. S. Ratnakar, 2000. Probucol protects against gentamicin induced nephrotoxicity in rats. Indian $J$ Pharmacol., 32: 108-113.

\section{How to cite this article: ss}

Arivuchelvan and Murugesan, S. 2020. Protective Effect of Ocimum sanctum in Broilers Treated with High Doses of Gentamicin. Int.J.Curr.Microbiol.App.Sci. 9(11): 2327-2332. doi: https://doi.org/10.20546/ijcmas.2020.911.279 